\title{
The role of steroids in treating diabetic macular oedema in the era of anti-VEGF
}

\author{
Tamir Weinberg ${ }^{1,2} \cdot$ Anat Loewenstein $^{3,4}$
}

Received: 11 November 2019 / Accepted: 28 November 2019 / Published online: 16 December 2019

(c) The Royal College of Ophthalmologists 2019

The prevalence of diabetes is increasing worldwide and with it its possible visual impairing sequelae [1]. Diabetic macular oedema (DMO) remains the main cause of visual impairment.

Although the pathogenesis of DMO is not fully understood, it involves three main components [2]. Vascular component, mediated by vascular endothelial growth factor (VEGF) including microaneurysms development and breakdown of blood-retina barrier. An inflammatory process in which pro-inflammatory proteins lead to capillary degeneration and pericyte loss. There is also a neurodegenerative process contributing to the pathological cascade.

Why then steroids, targeting the inflammatory part, should not be part of our armamentarium in treating DMO. According to recent PAT survey of the ASRS, over two thirds of ophthalmologists worldwide choose anti-VEGF as their first line of treatment of DMO [3]. By combating inflammatory cytokines, steroids have at least a theoretical role in the management of this disease.

Moreover, as has been shown by the Diabetic Retinopathy Clinical Research Network (DRCRnet) protocol I and protocol T, over $40 \%$ of patients still had persistent DMO despite adequate treatment with anti-VEGF [4, 5].

We have identified some subgroups of patients with DMO in whom steroids should be considered over the course of their disease management.

Tamir Weinberg

tamirw1@netvision.net.il

1 Hadassah School of Medicine, The Hebrew University of Jerusalem, Jerusalem, Israel

2 Department of Ophthalmology, Kaplan Medical Center, Derekh Pasternak, Bilu Junction, PO box 1, Rehovot, Israel

3 Sackler School of Medicine, Tel Aviv University, Tel Aviv, Israel

4 Department of Ophthalmology, Tel Aviv Medical Center, Tel Aviv, Israel

\section{Non-responding patients}

As mentioned, $40-60 \%$ of patients treated with an antiVEGF will have persistent oedema after an intensive treatment of six monthly injections, in these patients, visual acuity (VA) will not be as good as in the group without persistent oedema $[4,5]$.

\section{Non-compliant patients}

Widespread use of anti-VEGF agents has achieved a robust improvement in VA. Nevertheless, in order to achieve these improvements, patients have to be treated aggressively in the first year as has been shown in the pivotal trials. In the DRCRnet protocol $\mathrm{T}$, the median numbers of injections in year 1 were 9,10 , and 10 in the aflibercept, bevacizumab, and ranibizumab groups, respectively. In the following year, the injection number needed was reduced to 5, 6, and 6 injections [6]. In real world, the actual number of injections is much smaller and consists of 4.3 injections in the first year, and a much lower number in subsequent years [7]. As a result, VA outcome is lower in real life as compared with the pivotal trials. In order to avoid a less than optimal VA improvement in non-compliant patients, a slow release steroid implant may serve as a viable option.

\section{Pregnant women}

Despite lack of large prospective studies, it is suggested that due to the important role of VEGF in the development of the foetus, a potential damage may be inflicted to the foetus when using anti-VEGF. Several case series demonstrated a correlation between anti-VEGF injections to spontaneous miscarriages and preeclampsia when given at the first five weeks of gestation $[8,9]$. 


\section{Patients with recent arterial thromboembolic events (ATEs)}

The question whether intravitreal anti-VEGF agents increase the chances of ATEs is still under debate. In most randomized clinical trials [6, 10-12], patients with recent myocardial infarction or cerebrovascular accident were excluded from the study and by so, reducing the ability of the study to correctly asses the safety in this subgroup of patients. Systemic review and meta-analysis showed conflicting results. Thulliez et al. concluded that the studies and meta-analyses were not powered enough to correctly assess these risks [13], while Avery et al. did suggest a possible increased risk for ATEs [14].

In addition to these types of patients there are a few ocular findings in which the use of steroids has been claimed to be beneficial.

\section{Patients with hard exudates (HE) at the centre of fovea}

A postulated predictor of VA outcome is the presence of $\mathrm{HE}$, which may correspond to a less favourable VA outcome [15]. A post hoc analysis of the Bevordex study, comparing monthly bevacizumab to dexamethasone (DEX) implant every 16 weeks, demonstrated the different effect of these drugs on the regression of HE. This study showed that both groups resulted in decrease of the total area of HE but also showed a non-significant trend at 24 months in which more DEX-implant treated eyes had complete clearance of $\mathrm{HE}$. There was greater regression of $\mathrm{HE}$ from the fovea centre in the DEX-implant treatment group, which was statistically significant at 12 months but no longer at 24 months [16].

\section{Pseudophakic patients}

In large clinical trials studying the effects of intravitreal steroids in treating DMO, pseudophakic eyes were shown to have better VA outcomes compared with phakic eyes, namely the DRCRnet protocols B, I, U and the MEAD study group [17-20]. Because steroids accelerate cataract formation, we are less reluctant to use steroids in pseudophakic patients.

\section{Vitrectomised eyes}

It has been previously suggested in animal model by Chin et al. that the vitreous body may serve as a reservoir that helps prolong the therapeutic duration of medication administered intra-vitrealy [21]. Therefore, vitrectomised eye may benefit less from the therapeutic effect of an injected drug. In the Champlain study group, a single injection of DEX-implant was given, and patients were followed up for 26 weeks [22]. Overall at week 8, about $30 \%$ of patients gained $\geq 10$ letters suggesting the advantage of a slow release DEX implant.

\section{Is there a role for a combination therapy?}

In the DRCRnet, protocol U, pseudophakic patients with persistent DMO showed better VA outcome with combination treatment of ranibizumab and DEX implant compared with ranibizumab alone [20].

Given the above data, one cannot overlook the benefits of steroids when treating DMO with their ability to induce a longer therapeutic effect when given as an implant or insert and their relative safety in given circumstances in which anti-VEGF use is warranted.

New drugs emerge with pronounced anti-inflammatory effect like faricimab (Roche, Genentech) targeting both angiopoietin-2 and VEGF-A [23] and drugs with longer duration of action such as brolucizumab (Novartis) [24], and abicipar pegol (Allergan) [25]. New slow release devices such as the port delivery system will enable us to reduce the number of injections. Patient screening using artificial intelligence and deep learning will be more commonly used in the near future.

All these innovations may remodel the treatment paradigms for DMO. However, until these become available, patients may still benefit from steroids in the treatment of DMO.

\section{Compliance with ethical standards}

Conflict of interest The authors declare that they have no conflict of interest.

Publisher's note Springer Nature remains neutral with regard to jurisdictional claims in published maps and institutional affiliations.

\section{References}

1. Yau JWY, Rogers SL, Kawasaki R, Lamoureux EL, Kowalski JW, Bek T, et al. Global prevalence and major risk factors of diabetic retinopathy. Diabetes Care. 2012;35:556-64.

2. Tang J, Kern TS. Inflammation in diabetic retinopathy. Prog Retin Eye Res. 2011;30:343-58.

3. Global trends in retina ASRS 2018. In: Singh RP, Stone TW. editors. Chicago: IL, 2018. https://www.asrs.org/content/documents/ 2018-global-trends-in-retina-survey-highlights-website.pdf.

4. Bressler NM, Beaulieu WT, Glassman AR, Blinder KJ, Bressler $\mathrm{SB}$, Jampol LM, et al. Persistent macular thickening following intravitreous aflibercept, bevacizumab, or ranibizumab for 
central-involved DMO with vision impairment: a secondary analysis of a randomized clinical trial. JAMA Ophthalmol. 2018; 136:257-69.

5. Bressler SB, Ayala AR, Bressler NM, Melia M, Qin H, Ferris FL, et al. Persistent macular thickening after ranibizumab treatment for diabetic macular edema with vision impairment. JAMA Ophthalmol. 2016;134:278-85.

6. Wells JA, Glassman AR, Ayala AR, Jampol LM, Bressler NM, Bressler SB, et al. Aflibercept, bevacizumab, or ranibizumab for diabetic macular edema: two-year results from a comparative effectiveness randomized clinical trial. Ophthalmology. 2016;123:1351-9.

7. Willis JR, Morse LS, Rich W, Lum F, Salman C, Cantrell A. Treatment patterns for diabetic macular edema (DME) in the United States: analysis of the IRIS ${ }^{\circledR}$ registry (Intelligent Research in Sight). Honolulu, Hawaii: Paper presented at ARVO 2018; 2018.

8. Polizzi S, Mahajan VB. Intravitreal anti-VEGF injections in pregnancy: case series and review of literature. J Ocul Pharm Ther. 2015;31:605-10.

9. Petrou P, Georgalas I, Giavaras G, Anastasiou E, Ntana Z, Petrou C. Early loss of pregnancy after intravitreal bevacizumab injection. Acta Ophthalmol. 2010;88:e136.

10. Nguyen QD, Brown DM, Marcus DM, Boyer DS, Patel S, Feiner L, et al. Ranibizumab for diabetic macular edema: results from 2 phase III randomized trials: RISE and RIDE. Ophthalmology. 2012;119:789-801.

11. Korobelnik JF, Do DV, Schmidt-Erfurth U, Boyer DS, Holz FG, Heier JS, et al. Intravitreal aflibercept for diabetic macular edema. Ophthalmology. 2014;121:2247-54.

12. Brown DM, Nguyen QD, Marcus DM, Boyer DS, Patel S, Feiner $\mathrm{L}$, et al. Long-term outcomes of ranibizumab therapy for diabetic macular edema: the 36-month results from two phase III trials. RISE and RIDE. Ophthalmology. 2013;120:2013-22.

13. Thulliez M, Angoulvant D, Le Lez ML, Jonville-Bera AP, Pisella PJ, Gueyffier F, et al. Cardiovascular events and bleeding risk associated with intravitreal antivascular endothelial growth factor monoclonal antibodies: systematic review and meta-analysis. JAMA Ophthalmol. 2014;132:1317-26.

14. Avery RL, Gordon GM. Systemic safety of prolonged monthly anti-vascular endothelial growth factor therapy for diabetic macular edema: a systematic review and meta-analysis. JAMA Ophthalmol. 2016;134:21-9.

15. Sigurdsson R, Begg IS. Organised macular plaques in exudative diabetic maculopathy. Br J Ophthalmol. 1980;64:392-7.
16. Mehta H, Fraser-Bell S, Yeung A, Campain A, Lim LL, Quin GJ, et al. Efficacy of dexamethasone versus bevacizumab on regression of hard exudates in diabetic maculopathy: data from the BEVORDEX randomised clinical trial. $\mathrm{Br} \mathrm{J}$ Ophthalmol. 2016;100:1000-4.

17. Diabetic Retinopathy Clinical Research Network. A randomized trial comparing intravitreal triamcinolone acetonide and focal/grid photocoagulation for diabetic macular edema. Ophthalmology. 2008;115:1447-9.

18. Boyer DS, Yoon YH, Belfort R Jr, Bandello F, Maturi RK, Augustin AJ, et al. Three-year, randomized, sham-controlled trial of dexamethasone intravitreal implant in patients with diabetic macular edema. Ophthalmology. 2014;121:1904-14.

19. Diabetic Retinopathy Clinical Research Network. Expanded 2-year follow-up of ranibizumab plus prompt or deferred laser or triamcinolone plus prompt laser for diabetic macular edema. Ophthalmology. 2011;118:609-14.

20. Maturi RK, Glassman AR, Liu D, Beck RW, Bhavsar AR, Bressler NM, et al. Effect of adding dexamethasone to continued ranibizumab treatment in patients with persistent diabetic macular edema: a DRCR network phase 2 randomized clinical trial. JAMA Ophthalmol. 2018;136:29-38.

21. Chin HS, Park TS, Moon YS, Oh JH. Difference in clearance of intravitreal triamcinolone acetonide between vitrectomized and nonvitrectomized eyes. Retina. 2005;25:556-60.

22. Boyer DS, Faber D, Gupta S, Patel SS, Tabandeh H, Li XY, et al. Dexamethasone intravitreal implant for treatment of diabetic macular edema in vitrectomized patients. Retina. 2011;31:915-23.

23. Sahni J, Patel SS, Dugel PU, Khanani AM, Jhaveri CD, Wykoff $\mathrm{CC}$, et al. Simultaneous inhibition of angiopoietin-2 and vascular endothelial growth factor-A with faricimab in diabetic macular edema: BOULEVARD phase 2 randomized trial. Ophthalmology. 2019;126:1155-70.

24. Dugel PU, Koh A, Ogura Y, Jaffe GJ, Schmidt-Erfurth U, Brown DM, et al. HAWK and HARRIER: phase 3, multicenter, randomized, double-masked trials of brolucizumab for neovascular age-related macular degeneration. Ophthalmology. 2019; pii: S0161-6420(18) 33018-5. https://doi.org/10.1016/j.ophtha.2019.04.017. (In press)

25. Callanan D, Kunimoto D, Maturi RK, Patel SS, Staurenghi G, Wolf S, et al. Double-masked, randomized, phase 2 evaluation of abicipar pegol (an anti-VEGF DARPin therapeutic) in neovascularage-related macular degeneration. J Ocul Pharmacol Ther. 2018. https://doi.org/10.1089/jop.2018.0062. (In press) 